\title{
Manchester Ice Nucleus Counter (MINC) measurements from the 2007 International workshop on Comparing Ice nucleation Measuring Systems (ICIS-2007)
}

\author{
H. M. Jones ${ }^{1}$, M. J. Flynn ${ }^{1}$, P. J. DeMott ${ }^{2}$, and O. Möhler ${ }^{3}$ \\ ${ }^{1}$ Centre for Atmospheric Science, SEAES, University of Manchester, Manchester, UK \\ ${ }^{2}$ Department of Atmospheric Science, Colorado State University, Fort Collins, Colorado, USA \\ ${ }^{3}$ Institute for Meteorology and Climate Research, Karlsruhe Institute of Technology, Germany
}

Received: 27 July 2010 - Published in Atmos. Chem. Phys. Discuss.: 16 August 2010

Revised: 13 December 2010 - Accepted: 14 December 2010 - Published: 3 January 2011

\begin{abstract}
An ice nucleus counter was developed and constructed to enable investigation of potential ice nucleating materials. The Manchester Ice Nucleus Chamber (MINC) is a concentric-cylinder continuous flow diffusion chamber (CFDC). A full explanation of the MINC instrument is given here, along with first results and a comparison to an established instrument of similar design (Colorado State University CFDC) during sampling of common ice nucleating aerosols at the 2007 International workshop on Comparing Ice nucleation Measuring Systems (ICIS-2007). MINC and CSU-CFDC detected the onset of ice nucleation under similar conditions of temperature and supersaturation for several different types of ice nuclei. Comparisons of the ratio of ice nuclei to total aerosol concentrations as a function of supersaturation with respect to water $\left(\mathrm{SS}_{\mathrm{w}}\right)$ showed agreement within one order of magnitude. Possible reasons for differences between the two instruments relating to differences in their design are discussed, along with suggestions to future improvements to the current design.
\end{abstract}

\section{Introduction}

Aerosol particles may influence climate directly by the scattering and/or absorption of radiation and indirectly through their role as cloud condensation nuclei $(\mathrm{CCN})$ or ice nuclei (IN). IN are defined as the subset of aerosol particles that catalyse the formation of ice crystals (Vali, 1985). The existence of atmospheric IN and the role they play in cloud

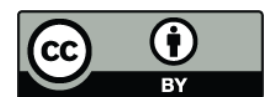

Correspondence to: $\mathrm{H}$. M. Jones (hazel.jones@manchester.ac.uk) formation implies that they have the ability to affect the local radiation budget; changes in cloud microphysics will change the scattering and reflective properties of cloud (e.g. DeMott et al., 2010a). Without IN, clouds would not glaciate until temperatures approach the $\sim-40^{\circ} \mathrm{C}$ limit for homogeneous ice nucleation, with pure water droplets beginning to freeze at $-36^{\circ} \mathrm{C}$ (DeMott et al., 2003a; Vali, 1996). Glaciation is frequently observed at much higher temperatures due to the presence of atmospheric IN. Measurements of these atmospheric IN is the focus of the current study. There are currently four recognised fundamental heterogeneous ice nucleation mechanisms: deposition nucleation (vapour transferred directly to the IN surface), condensation-freezing (water condenses onto the surface of the IN to form a supercooled droplet, then subsequently freezes), contact-freezing (supercooled water droplet freezes upon contact with the IN) and immersion-freezing nucleation (IN becomes immersed inside a supercooled water droplet, then subsequently freezes), (Vali, 1985).

While it is recognised that ice nucleation is of critical concern for weather and climate models, there are major short-comings in our ability to treat this process reliably (e.g. Forster et al., 2007). One reason for this is the paucity of reliable measurements and the need for more extensive continuous measurements of IN that will ultimately allow more accurate parameterisations to be produced for use in models (e.g. DeMott et al., 2010a). There are many difficulties relating to the identification and measurement of IN. IN may act in supercooled water or supersaturated vapour, or at the interface between the two phases. Typical atmospheric concentrations of IN are $\sim 1 \mathrm{stdL}^{-1}$ at $-20^{\circ} \mathrm{C}$ and $\sim 10 \mathrm{stdL}^{-1}$ at $-30^{\circ} \mathrm{C}$ (DeMott et al. 2010a). This is around 6 orders of magnitude less than typical urban total atmospheric aerosol

Published by Copernicus Publications on behalf of the European Geosciences Union. 
concentrations. However, it is important to consider that IN concentrations can be subject to very large variations in time and space. In addition, physical or chemical processes may alter the effectiveness of any given IN, (Szyrmer and Zawadzki, 1997). There are two ways in which to predict IN concentrations in models: use aerosol properties in conjunction with either lab studies or a constrained theoretical approach on the effects of aerosol properties on ice nucleation (e.g. Meyers et al., 1992), or to use climatologies of IN concentrations (e.g. Bigg, 1990). When measuring IN in the laboratory or in the atmosphere, they may only be detected and counted by observing the ice crystals formed from them at given temperatures and supersaturations. The multitude of possible ice nucleation processes within the atmosphere makes realistic simulations of all natural atmospheric conditions within measuring systems difficult and most measurement techniques are insensitive to one or more modes of activation.

Greater interest in the research field of ice nucleation is being spurred by the increasing demand for knowledge concerning ice clouds in the atmosphere and the important contribution they make to regional and global hydrological pathways. Although secondary ice formation mechanisms like the Hallett-Mossop process (Hallett and Mossop, 1974) can be extremely important for the ultimate glaciation of clouds warmer than $-8{ }^{\circ} \mathrm{C}$, ice nuclei are likely the cause of initial glaciation (with the exception of glaciation by homogeneous freezing or the 'seeder-feeder' mechanism, see Bergeron, 1965). Measurements of IN are therefore of paramount importance in order to obtain information concerning their abundance, activity, constituents and major regional global sources as well as their temporal diurnal and seasonal variations; without these measurements, accurately predicting ice cloud initiation and development in particular meteorological situations will remain a limiting factor to providing better weather and regional climate prediction models. Several instrument exist that are capable of measuring ice nucleation properties, these include static diffusion chambers (e.g. Kanji and Abbatt, 2006; Knopf and Koop, 2006; Dymarska et al., 2006, Kulkarni et al., 2009) and continuous flow diffusion chambers (e.g. Stetzer et al., 2008; Rogers 1988). Developing instrument such as these, allows an increased collection of IN data, a clear need. The existence of so few of these instruments provides motivation into the development of new instruments to provide additional data to allow the progression of ice nucleation parameterisations and reduce the uncertainty in cloud microphysics models.

This paper describes a Continuous Flow Diffusion Chamber (CFDC) instrument developed for field and laboratory use at the University of Manchester. This instrument is capable of detecting all modes of ice nucleation except contactfreezing nucleation, although there is no means to easily discern the combination of mechanisms near and above water saturation. Details of the operation principles, hardware and software are given. Calibration and operational procedures are also outlined. Initial results obtained at the International Workshop on Comparing Ice Nucleation Measuring Systems - 2007 (ICIS-2007) (see Sect. 3), along with a comparison to other instruments present at the workshop are shown and discussed. Suggestions for future development are outlined in Sect. 6.

\section{The Manchester Ice Nucleus Chamber (MINC)}

Previous work on IN measurements at the University of Manchester included the design and construction of flat-plate continuous flow diffusion chambers, initially of horizontal configuration and later of vertical configuration (Hussain and Saunders, 1984) in an attempt to reduce particle losses in the chamber. Results from these chambers were used as part of the IN parameterisation developed by Meyers et al. (1992), a parameterisation, or derivations thereof, still widely in use. However, these early flat plate instruments were found to suffer edge effects and were bulky, making them difficult to transport and unsuitable for aircraft use, although recent flatplate designs appear to have resolved these problems (e.g. Stetzer et al. 2008). As a consequence of this previous work, the Manchester Ice Nucleation Chamber (MINC) was designed as a Continuous Flow Diffusion Chamber (CFDC) of the cylindrical design based on the laboratory instrument first described in Rogers (1988). The main aspects of this design are described below.

\subsection{Principle of operation}

In MINC, supersaturated conditions are established between the ice-coated walls of two vertically-orientated, concentric cylinders maintained at different temperatures. In the region between the two ice-covered walls, almost linear steady-state vapour pressure and temperature fields are established. Equilibrium vapour pressure is an exponential function of temperature and therefore the region between the walls is supersaturated with respect to ice, with the degree of supersaturation determined by the temperature difference between the walls and the distance from the walls (Rogers, 1988). Humidities from ice saturation to well in excess of water saturation can be achieved with this system. Sample air is injected into the central region of laminar flow at the top of the chamber, sandwiched between two layers of dry, filtered air. This ensures that the sample environment is narrow and well defined. It is important that the flow be laminar so that the sample environment can be accurately determined. Poiseuille flow within the chamber results in a parabolic velocity profile due to the wall separation being small compared to the cylinder radii (Knudsen and Katz, 1958). In the older horizontal flat plate designs, the aerosol laminar remained centred between the plates, but with vertical chambers there is the added complication of buoyant circulation due to the temperature gradient, (Sinnarwalla and Alofs, 1973): air near the cold 
wall will tend to sink; air near the warm wall will tend to rise. This results in a skewed velocity profile and displacement of the lamina and maximum supersaturation region towards the cold wall. If the temperature difference between the walls becomes too great then negative flow may result. This could lead to undesirable influences on the sample air stream so the flow conditions are monitored in real-time using calculations given by Rogers (1988). An "evaporation section" at the bottom of the chamber uses an non-cooled plastic outer (warm) wall while retaining the cold and ice-covered cold wall to allow the vapour and temperature fields to relax to the cold wall conditions, with the intent to keep the air slightly supersaturated with respect to ice but not with respect to water. This allows any water droplets formed in the first part of the chamber to be removed by either the Bergeron-Findeisen process (e.g. Rogers and Yau, 1989) whereby ice crystals grow at the expense of water droplets (fairly minor), or by diffusional loss of vapour to the cold wall. Detection of ice crystals by particle size only using an optical particle counter (OPC) is then possible.

\subsection{Instrument design}

The MINC instrument is housed inside a custom built aluminium frame, $159 \mathrm{~cm} \times 72 \mathrm{~cm} \times 20 \mathrm{~cm}$. The instrument, premounted in the frame, can be transported and located in the laboratory or in the field. The following sections outline the construction and design elements of various MINC components.

\subsubsection{The chamber}

The chamber itself consists of two vertical, concentric copper cylinders ( $1 \mathrm{~mm}$ wall thickness) with outer diameters of $98 \mathrm{~mm}$ and $76 \mathrm{~mm}$, between which exists a $10 \mathrm{~mm}$ annular gap. It is in this gap that supersaturated conditions are developed as described in Sect. 2.1. This annular arrangement avoids the edge effects present in chambers of the flat-plate design (e.g. Al-Naimi and Saunders, 1985), and the vertical arrangement avoids gravitational loss of particles. The chamber walls are iced by pumping water into the outlet of the CFDC chamber, with the chamber having been pre-cooled to $-30^{\circ} \mathrm{C}$. The chamber is quickly filled to a level $10 \mathrm{~cm}$ lower than the chamber inlet manifold, then is promptly pumped back out again such that during this time the wall temperatures do not rise above $0{ }^{\circ} \mathrm{C}$. To increase the hygroscopicity of the copper wall surface, to allow a smooth ice layer to be applied, the walls were treated with an 'ebonizing' solution that reacts with the copper to form a thin layer of black cupric sulphide crystals (see Rogers et al. 2001): this provides a hydrophilic surface to allow a uniform ice coating $(\sim 0.1 \mathrm{~mm}$ thick - tested via the collection of melt water). The total length of the chamber is $750 \mathrm{~mm}$, with the bottom $250 \mathrm{~mm}$ of the outer wall made of insulating hydrophobic plastic; this is the water droplet evaporation zone. This section of the outer wall warms to $0^{\circ} \mathrm{C}$ during icing and it is not expected to retain any ice coating. Residence time in the system (from instrument inlet to detection system) is $\sim 10 \mathrm{~s}$ (latter $4 \mathrm{~s}$ in the evaporation section), during which time crystals may grow in the chamber and then be detected by passing through a particle counter at the exit of the chamber. The wall temperatures are monitored using thin film Platinum Resistance Thermometers (PRTs, class A, 4-wire PT-100, $\pm 0.15^{\circ} \mathrm{C}$ ) at three positions along each wall; they are henceforth labelled top, middle and bottom, for the inner and outer wall. Using these measured temperatures, sample laminar supersaturation was calculated using the equations for saturation vapour pressure given in Murphy and Koop (2005). The chamber is insulated with aluminium coated bubble wrap (4mm thick Aluminium thermal foil, B\&Q) and then Armaflex insulation sheeting ( $20 \mathrm{~mm}$ thick) that also prevents condensation. This is all encapsulated inside a metal frame box and fixed to the rack to increase stability.

With instruments of this design, there are two main design issues that must be accounted for: wall effects and transient supersaturations. Wall effects (loss of aerosol to chamber walls) can be minimised by keeping the aerosol laminar away from the walls and using a large aspect ratio (length of cylinder: annular space= 75 for MINC), (e.g. Elliott, 1971). Transient supersaturations can occur at the top of the chamber if the incoming sample air is saturated and colder than the sheath air. Transient supersaturations need to be avoided as they momentarily increase the local supersaturation potentially activating some aerosol particles which would have otherwise remained inactivated, thus giving false readings. This problem can be minimised in two ways, either by preconditioning the sample (e.g. Saxena et al., 1970) or delaying the vapour diffusion region until conditions are settled (Fukuta and Saxena, 1979). The current design uses both preventative methods by recycling the cold dry sheath air, drying the incoming sample air and leaving the top $10 \mathrm{~cm}$ of chamber ice free.

\subsubsection{The refrigeration system}

The temperature of each wall is controlled independently by its own refrigeration system, see Fig. 1. Each system is required to provide a stable steady temperature along the length of the chamber wall. Copper tube (3/8 in outer diameter, $1 \mathrm{~mm}$ wall thickness) is soldered to the outside of the copper section of the outer wall in a coil arrangement, with a $5 \mathrm{~cm}$ space between each coil. The inner coil stretches the full length of the inside wall, it is not soldered to the wall due to spatial constraints, but is immersed in heat transfer fluid (Polydimethyl Siloxane) to increase the thermal contact with the wall. All externally exposed refrigeration pipes are insulated with Armaflex tubing to avoid reducing the efficiency of the refrigeration system and to minimise frosting. Two compressor units (Electrolux, CML90FB3) - one for each wall circulate R404A refrigerant around each system. 


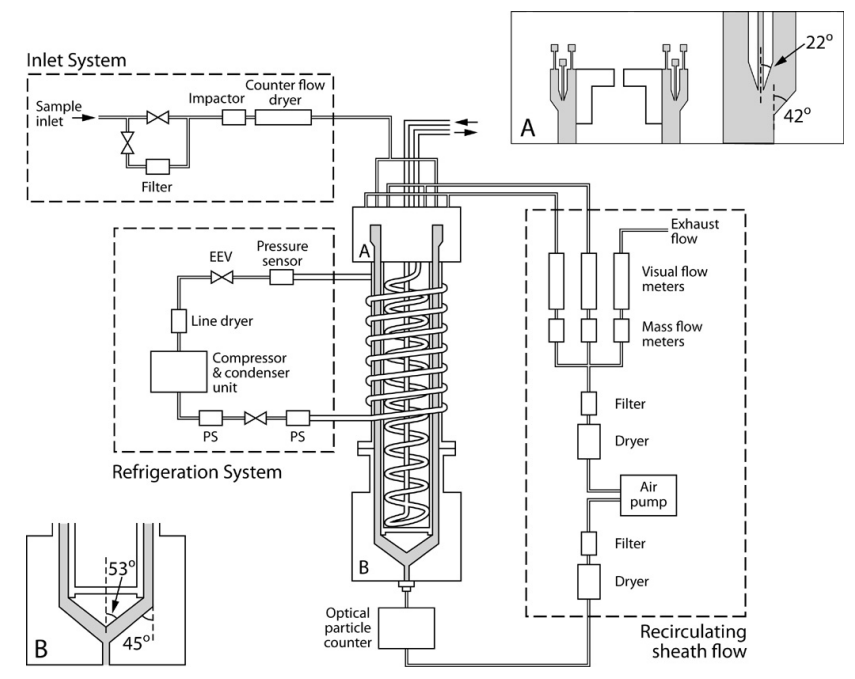

Fig. 1. Schematic of the MINC instrument separated into different systems: sample inlet, recirculating sheath flow system, refrigeration system and the chamber. The figure shows the outer wall refrigeration system only. The inner wall system is of the same arrangement, where the refrigerant enters/exits the coil via the arrows shown. $\mathrm{PS}=$ pressure sensor, $\mathrm{EEV}=$ electronic expansion valve, $\mathrm{OPC}=$ optical particle counter, see main text for description. A close up of the entrance and exit to the chamber are labelled as $\mathrm{A}$ and $\mathrm{B}$ respectively.

An electronic expansion valve (Sporlan, SEI 0.5-10-S) connected to the outlet of each compressor is controlled by the user and determines the temperature of the coil, and hence the chamber wall. Refrigerant pressure is measured (Sensortechnics, CTE9020GY4) before and after the coil, and a second expansion valve (Sporlan, SEI-0.5-11-S) after the coil is used to maintain the pressure across the coil. Equalised pressure results in equal cooling along the wall, and so a steady wall temperature.

\subsubsection{The airflow system}

Sample air (1 LPM) initially passes through the inlet system, which consists of an impactor (design as per Rogers et al. 2001) that has a nominal $1.3 \mu \mathrm{m} \mathrm{50 \%} \mathrm{cut-off} \mathrm{to} \mathrm{remove} \mathrm{larger}$ particles and a counter-flow gas drying column (Permapure Nafion, PD-100T) to remove any moisture from the sample that would result in frosting of the inlets and consequently lead to false readings due to ice splinter formation and release into the sample stream. The inlet system also has a set of valves that allow a clean-room grade particle filter (HEPA, removing at least $99.97 \%$ of airborne particles $0.3 \mu \mathrm{m}$ in diameter) to be place in-line ahead of the impactor and so allow a background test to ensure there is no frosting in the chamber.

As outlined in Sect. 2.1, this sample air enters the chamber between two layers of dried, particle free air (4.5 LPM each). The sheath air is dried by passing it through a desic- cant drying column (Drierite, size 8 mesh) and then filtered (HEPA filter), see Fig. 1. Air exits the bottom of the chamber through the OPC (see Sect. 2.2.4) and then passes through the air flow pump, a drier and filter to provide the counter-flow to the inlet drier. After the inlet drier, the airflow passes a second dryer and filter before the flow (10 LPM) is split, with 1 LPM forming an exhaust flow and the remainder being recirculated to form the two sheath flows. A pressure relief valve is provided at the top of the chamber for use during the wall icing process.

\subsubsection{The detection system}

Ice crystals are expected to grow up to sizes of $\sim 10 \mu \mathrm{m}$ (Rogers, 1988), depending on sample temperature and supersaturation, during an approximate chamber residence time of $10 \mathrm{~s}$ (with $6 \mathrm{~s}$ exposure to steady supersaturation conditions). The growth of ice crystals to sizes larger than the incoming aerosol sizes, and the evaporation of any water droplets that form in cases when operating above water saturation, allows the reliable detection of ice crystals based on particle size. Air exiting from the bottom of the chamber is immediately drawn through an optical particle counter (OPC, CLiMET 3100-1158) modified by the removal of an internal critical orifice to operate at 10 LPM, to detect and size crystals.

\subsubsection{Software}

Software written in-house using the LabVIEW development system (National Instruments, LabVIEW 7.0) and running on a standard PC is used to monitor and record data from the MINC at one second intervals. Wall temperatures, refrigeration pressures, air flow temperatures, air pressure, air flow rates and OPC data are constantly monitored via NuDam data acquisition modules (ND 6013, ND 6017, ND 6520). The program also allows the user to control the refrigeration valves using a relay output board (Amplicon, PCI 236).

\subsection{Calibration}

\subsubsection{Aerosol losses}

The sample inlet system is described in Sect. 2.2.3 of the main text. Due to the nature of the system, size dependent losses are expected and so these should be corrected for when considering the ratio of measured ice nucleating particles to the total aerosol population (known as "activated fraction" $(\mathrm{AF})$ ). To calibrate the inlet losses a polydisperse distribution of ammonium sulphate particles was provided by a TOPAZ aerosol generator. The size distribution of these aerosol was measured before and after the inlet system using a Differential Mobility Particle Sizer (DMPS, please see Williams et al., 2007 for details on the operation of this instrument). Total aerosol concentrations during these tests were of the order of $10^{6}$ particles per cubic centimetre. During these tests, the counterflow to the inlet drier was provided by the 


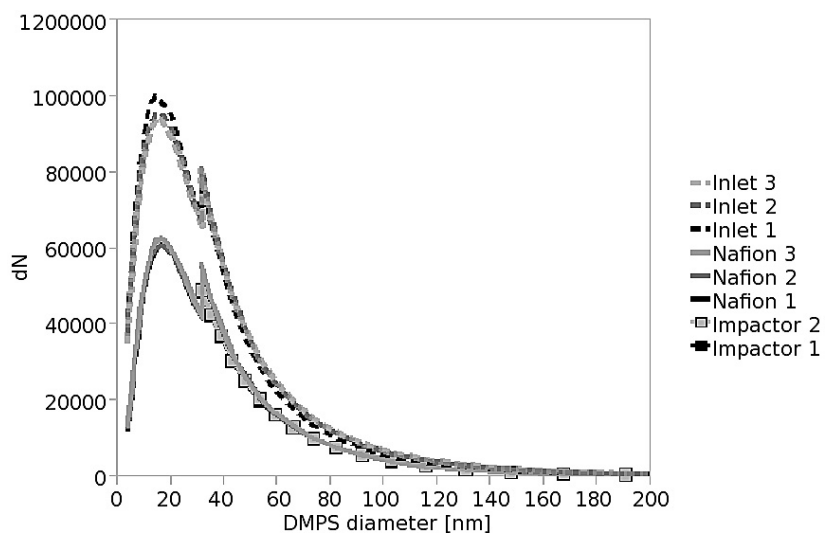

Fig. 2. DMPS size distribution scans for the inlet system, showing results from before and after the inlet system as denoted by the figure legend.

MINC airflow system as in normal condition of operation, while the inlet flow was provided by a Condensation Particle Counter (CPC, TSI 3025A), part of the DMPS system. Figure 2 shows the measured aerosol size distributions for DMPS scans at the start of the inlet system (direct to the TOPAZ aerosol source), scans after the drier, and then scans after the drier and the impactor. As can be seen from Fig. 2, for this size range, most of the aerosol losses are due to the counterflow drier.

Using the information given in Fig. 2, a size dependent transmission curve can be obtained. This is shown in Fig. 3: the transmission curve is shown for sizes $5-500 \mathrm{~nm}$. For sizes $500-1000 \mathrm{~nm}$ the transmission is assumed to be $40 \%$ as a continuation of the curve in Fig. 3 levelling off to this value. At sizes $>1000 \mathrm{~nm}$, the transmission curve for the impactor is then implemented.

The impactor transmission and 50\% cut-off were tested using a similar technique as described above. To test the size range of the impactor, a GRIMM optical particle counter (model 1.108) was used to sample laboratory air directly, and then through the impactor: this data is shown in Fig. 4. The $50 \%$ cut-off was found to be at $1.3 \mu \mathrm{m}$, with $75 \%$ transmission at $0.8 \mu \mathrm{m}$ and $25 \%$ transmission at $1.7 \mu \mathrm{m}$.

The low transmission efficiency curve described above is primarily due to diffusional losses of smaller particles in the Nafion counterflow drier, and impaction losses of larger particles in the impactor and also in the connections between inlet parts. Coagulation is not thought to play a role here.

During the ICIS-2007 experiments, the size distribution of the aerosol population in the APC chamber was not measured continuously, so applying a size dependent correction to the incoming sample aerosol could not be performed. Total aerosol number concentration was measured continuously, so we must provide a correction to this number. This was done by comparing the calculated total number from the APC chamber non-corrected and corrected size distribution infor-

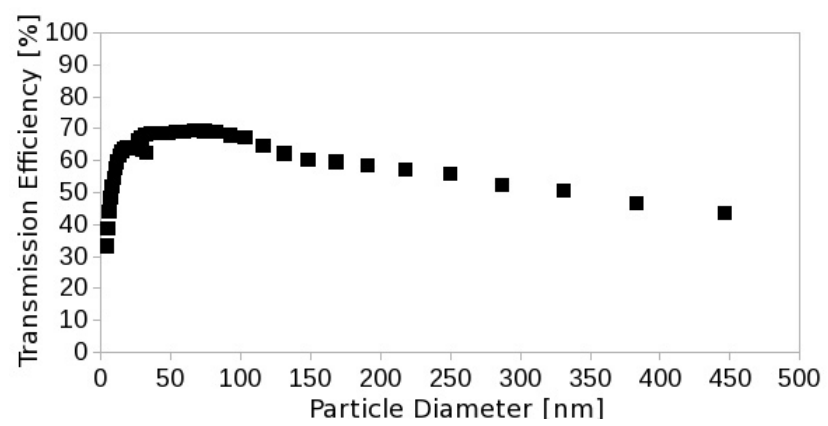

Fig. 3. Transmission curve (shown here from 0-500 nm) of aerosol particles through the MINC inlet system.

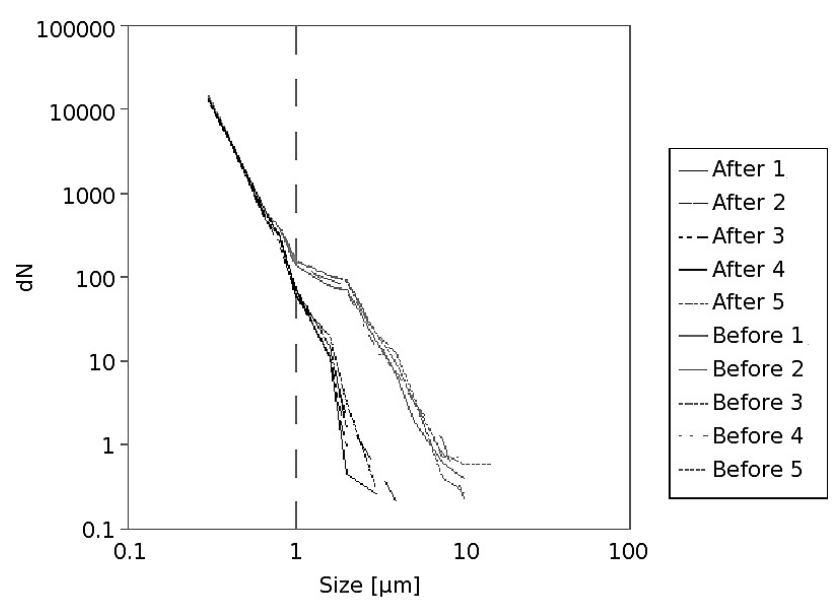

Fig. 4. GRIMM size distribution for the impactor. Results are shown for before and after the inlet system as denoted by the figure legend.

mation. For each sample, the comparison was made for the size distribution information available across the measurement period. The transmission fraction of aerosol particles was found to be constant for size distribution data collected after approximately one hour had passed since the aerosol was injected. MINC results used in this paper were taken after an hour had passed. Transmission co-efficients used for this study are $0.55,0.57$ and 0.63 for ATD, SD and Snomax ${ }^{\circledR}$ respectively.

In future experiments, it would be beneficial to measure the size distribution of aerosol at the inlet to the chamber continuously to allow more accurate results to be obtained.

\subsubsection{Wall temperature}

As the temperature of each wall is not measured directly on the inside of the chamber, it is important to know how the recorded temperatures (measured at the back of the copper surface) relate to the ice surface temperatures. It is important to know this as it is these temperatures that are used to 

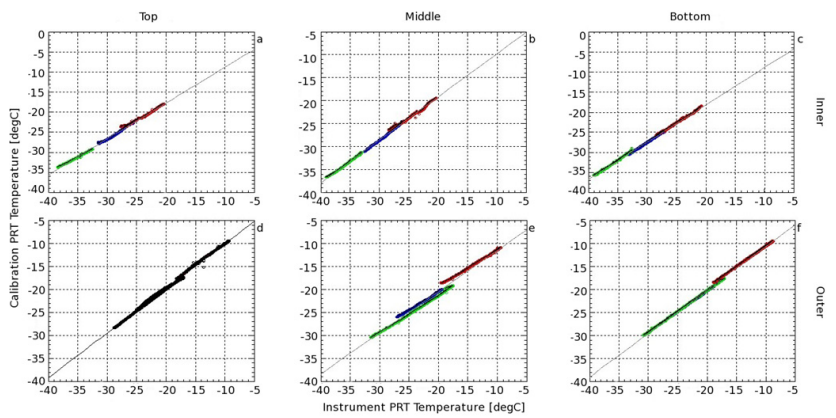

Fig. 5. Temperatures as measured by instrument PRTs (x-axis) plotted against temperatures as measured by calibration PRTs* (y-axis) for three different start temperatures $\left(-18^{\circ} \mathrm{C},-25^{\circ} \mathrm{C},-30^{\circ} \mathrm{C}\right)$ * Deviations from straight-line fit for outer wall middle temperatures was due to calibration sensor not being firmly fixed to the wall.

calculate the sample temperature and supersaturation conditions.

The instrument has three Platinum Resistance Thermometers (PRTs) on each wall, positioned at the top, middle and bottom of the copper sections (where the top and bottom PRTs are positioned $5 \mathrm{~cm}$ from the end of the copper tube). In order to calibrate the temperature difference between where we want to know the temperature (the inside walls of the chamber) and where we actually measure it (on the outside surface of the chamber), calibrated PRTs were placed inside the chamber against the copper wall at corresponding positions to the instrument PRTs. The walls were then cooled/warmed under conditions typical of those used at ICIS-2007. Typical airflow was also used to allow representative results, though the ice coating could not be applied as there was no way to seal the chamber as the calibration PRT wires must go through the chamber outlet. The calibration was performed at three different start temperatures to determine if start temperature has any effect on the results, this is shown in Fig. 5. Figure 5 has six panels, one for each of the instrument PRTs. It can be seen in each of these plots that a common straight line fit can be used for all three starting temperatures, indicating that starting temperature does not affect the calibration and that a simple correction can be made to each measurement.

Outer wall instrument temperatures agreed well with the calibration temperatures, mostly within $0.5^{\circ} \mathrm{C}$. However, the inner wall instrument temperatures reported up to $5^{\circ} \mathrm{C}$ lower temperatures than the calibration PRTs, especially when operating at very low temperatures. The measurements at the top of the inner wall showed the most difference between instrument and calibration PRT values: $2{ }^{\circ} \mathrm{C}$ difference at $-20^{\circ} \mathrm{C}$ and $5^{\circ} \mathrm{C}$ at $-40^{\circ} \mathrm{C}$. Whereas the middle of the inner wall temperature comparison showed $0^{\circ} \mathrm{C}$ difference at $-20^{\circ} \mathrm{C}$ and $3^{\circ} \mathrm{C}$ difference at $-40^{\circ} \mathrm{C}$.
The other piece of important information that these results show is that there does not appear to be a steady temperature along each of the walls. For example, consider the highest point on each of the outer temperature graphs in Fig. 5. The middle temperature is lower than the two ends. The same is true when considering the inner wall temperatures. Investigations using additional PRTs along the inside of each wall revealed that wall temperatures were steady along most of each wall, with temperature increasing slightly within $\sim 10 \mathrm{~cm}$ at each end. This is mainly due to heat gain from the ends of the chamber.

\subsubsection{Optical particle counter}

The Optical Particle Counter (OPC) used was a CLiMET 3100-1158. As the OPC was operated at a lower flow rate than standard (28.3 LPM) a peak voltage to size calibration was provided at purchase. The OPC outputs two continuous analogue signals - designated high gain and low gain, from which concentrations in the $1-2 \mu \mathrm{m}$ particles channels and 3-8 $\mu \mathrm{m}$ particles channels respectively were derived (channels are named according to channel lower size limit) using in-house built electronics which send the counts to the computer (via National Instruments, 6602). The counting efficiency of the high gain channel is reported as $50 \% \pm 10 \%$ for the lowest bin $(1 \mu \mathrm{m})$, whereas the low gain channel counting efficiency is reported as $100 \% \pm 10 \%$ for the lowest bin $(3 \mu \mathrm{m})$. The OPC sampled the total flow from the chamber. Ice particle numbers detected in the total flow are related to the sample flow to determine nucleated IN number concentrations.

To confirm that the electronics, as part of the OPC system, were able to size particles correctly, the modified CliMET was compared in the laboratory to a calibrated OPC (Grimm Aerosol Tecnik, Dust Monitor 1.105, optical scattering size range 0.5-20.0 $\mu \mathrm{m}$ ) and an Aerodynamic Particle Sizer (TSI APS 3321, aerodynamic size range 0.5-20.0 $\mu \mathrm{m})$. A Vibrating Orifice Aerosol Generator (VOAG) was used to produce monodisperse aerosol at known sizes $(3,4,5 \mu \mathrm{m})$ using $\mathrm{NaCl}$, oleic acid and olive oil solutions. Size distributions from all instruments peaked at the same size (to within $1 \mu \mathrm{m}$ ), but the CLiMET exhibited a broader distribution than the other instruments, typically spanning over three size channels, equivalent to the peak size $\pm 2 \mu \mathrm{m}$. The APS has higher resolution due to many more channels than the CLiMET, and the distribution tended to span over $\sim 6$ size channels, roughly equivalent to peak size $-1 /+2 \mu \mathrm{m}$. GRIMM OPC results were harder to discern due to the smaller number of size bins and the staggering of the bin sizes. Typically, peaks spanned two or three size bins, e.g. when measuring $5 \mu \mathrm{m}$, sizes from 3.5$7.5 \mu \mathrm{m}$ were seen. 
Table 1. ICIS-2007 sample information.

\begin{tabular}{|c|c|c|}
\hline Date & Sample & Notes \\
\hline $17 / 09 / 07$ & ATD & $\begin{array}{l}\text { Commonly used in past IN } \\
\text { studies. Mechanically pro- } \\
\text { duced by Particle Technol- } \\
\text { ogy Inc. Representative of } \\
\text { SW US desert dust }\end{array}$ \\
\hline \multicolumn{3}{|l|}{$18 / 09 / 07$} \\
\hline \multicolumn{3}{|l|}{$19 / 09 / 07$} \\
\hline 20/09/07 & Soot & $\begin{array}{l}\text { Generated by graphite spark } \\
\text { generator }\end{array}$ \\
\hline \multicolumn{3}{|l|}{$21 / 09 / 07$} \\
\hline $24 / 09 / 07$ & Israeli Dust & $\begin{array}{l}\text { Collected sample after Israeli } \\
\text { dust storm }\end{array}$ \\
\hline $25 / 09 / 07$ & Saharan Dust & $\begin{array}{l}\text { Collected sample from near } \\
\text { Cairo }\end{array}$ \\
\hline 26/09/07 & Canary Island Dust & $\begin{array}{l}\text { Collected sample from re- } \\
\text { gion exposed to deposition } \\
\text { from Saharan aerosol layers }\end{array}$ \\
\hline 27/09/07 & Snomax ${ }^{\circledR}$ & $\begin{array}{l}\text { Manufactured IN protein, } \\
\text { York Snow Company }\end{array}$ \\
\hline 28/09/07 & Live Bacteria & Pseudomonas syringae \\
\hline
\end{tabular}

\section{International workshop on Comparing Ice nucleation measuring Systems (ICIS) 2007}

The International workshop on Comparing Ice nucleation measuring Systems (ICIS) 2007, also dubbed the Fourth International Ice Nucleation Workshop, was held at the Aerosol, Interactions and Dynamics in the Atmosphere (AIDA) chamber facility at the Institute for Meteorology and Climate Research (IMK), Karlsruhe Institute of Technology (KIT), Germany. The main objective of this workshop was to compare and contrast currently existing ice nucleation measurement instruments using a common, well characterised, aerosol generation system, a revived concept from earlier workshops, the third being in Laramie, Wyoming, 1975 (Vali, 1975). The purpose of this was to assess the range and consistency of present IN measurement capabilities. Details of all instruments and their respective research groups are given in the ICIS-2007 overview paper (Möhler et al., 2008a; DeMott et al., 2010b). Experiments were carried out between 17 September 2007 and 28 September 2007. Aerosol samples were chosen for their expected ice nucleation properties, details of which are summarised in Table 1.

Samples were prepared so that the vast majority of particles used in the experiment were $<1 \mu \mathrm{m}$ diameter; thus allowing those instruments without impactors on their inlets to identify IN more easily based only on measured particle size. Dust samples were always dispersed in the same way, as described in Möhler et al. 2006, with the cyclone impactor
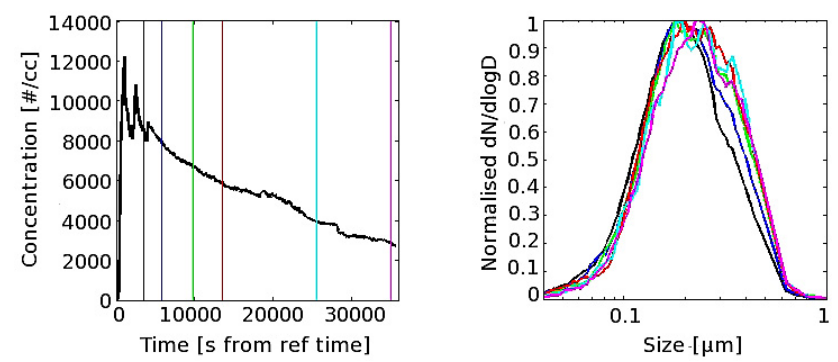

Fig. 6. a) Total aerosol concentration time series during 19/09/07 with vertical lines representing the times at which the b) size distributions were taken shown. Size distributions are shown for times $3420,5820,9790,13500,25600,35000$ s from the reference time.

set to remove the larger dust particle fraction. The Snomax ${ }^{\circledR}$ sample was dispersed from a water suspension, as described in Möhler et al., 2008b. Aerosol particles were introduced to the Aerosol Preparation and Characterisation (APC) Chamber at typical initial concentration of up to $10^{5} \mathrm{~cm}^{-3}$. IN detection instruments could then sample directly from this chamber, during sampling number concentrations were typically at or below around $10^{4} \mathrm{~cm}^{-3}$. Figure 6 shows the typical variation in aerosol properties in the APC chamber throughout the day. Figure 6a shows the total aerosol concentration varied with time and Fig. 6b shows the size distributions (normalised to maximum value) at various times during the day, see caption and also dashed lines on Fig. 6a. As can be seen, the peak of the size distribution is shifting to slightly higher sizes throughout the day as the total concentration decreases significantly. These changes to the aerosol population are probably the result of particle coagulation and losses. After aerosol size characterisation, a minor fraction of the aerosol was transferred to the much larger AIDA chamber (resulting in concentrations of $\sim 500 \mathrm{~cm}^{-3}$ ) for cloud nucleation expansion experiments. There was an opportunity for sampling from the AIDA chamber prior to an expansion run. The AIDA chamber walls were pre-coated with ice to establish ice saturation at wall temperature. The whole chamber was cooled to sub-zero temperatures, and then the air inside the chamber was further cooled by adiabatic expansion, e.g. Möhler et al., 2003. During an expansion, a suite of instruments including particle counters are used to determine the activation point and evolution of ice nucleation as a function of temperature and supersaturation. AIDA expansion experiments were carried out for all samples in Table 1. Further information can be found in Koehler et al. (2010).

This paper reports the results obtained by the MINC instrument described in the previous section. Also shown are comparisons with the CSU-CFDC instrument, an instrument of similar design, but with some notable differences. The CSU-CFDC is the same version $(\mathrm{CFDC}-1 \mathrm{H})$ which was used in recent laboratory and field studies (e.g. Eidhammer et al., 2010; Richardson et al., 2010). 

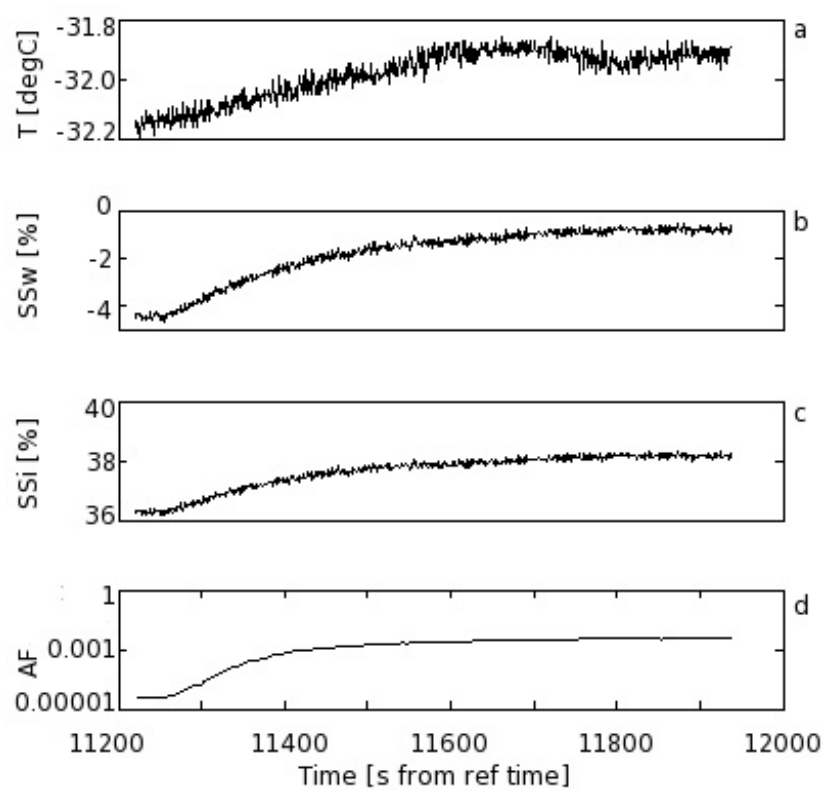

Fig. 7. A typical SS-scan, performed for ATD sample. (a) Sample temperature time series, (b) SSw time series, (c) SSi time series, (d) Number of particles $>3 \mu \mathrm{m}$ versus time for the SS-scan.

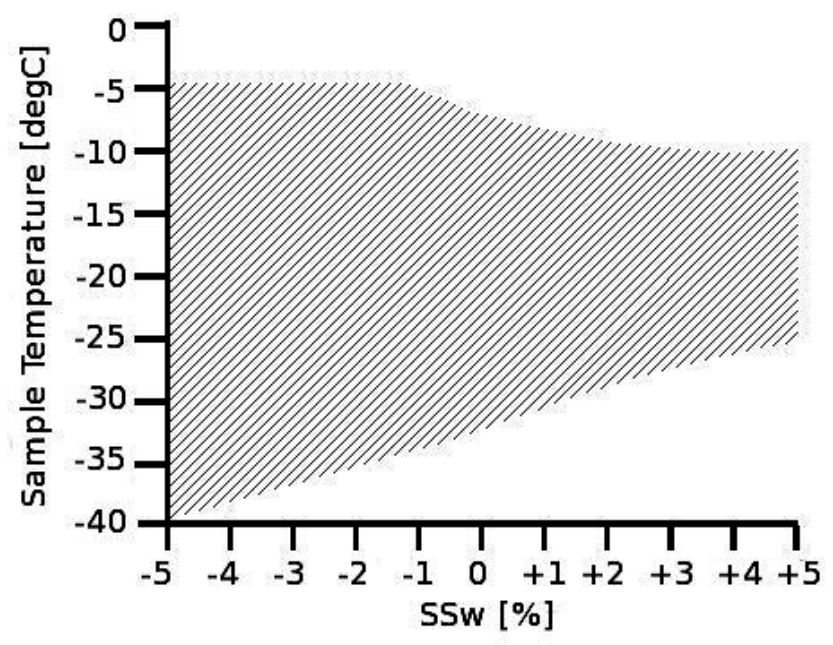

Fig. 8. The range of sample conditions possible within the MINC chamber as indicated by the hatched area on this Sample temperature versus SSw.

The CSU-CFDC design differs from the MINC design primarily in the use of an actively cooled evaporation section, and does not have heat-transfer fluid within the inner wall: instead the copper pipes have been directly attached to the inside wall surface. The CSU-CFDC is also longer than the MINC chamber, with the CSU-CFDC chamber section being $81 \mathrm{~cm}$ in length, with a reduced length of non-iced wall below the inlet manifold. Although the function of elements of the inlet section are the same, the physical arrangement and actual components used are different, such that the MINC experiences a lower transmission efficiency than the CSUCFDC (0.8-0.9 for particles $>100 \mathrm{~nm})$. This discrepancy in the transmission efficiency between the two instruments is mainly due to the use of the Nafion counter-flow dryer in the MINC system, where the losses are much more extreme than those experienced in diffusion driers which the CSU-CFDC system employs.

\section{Results}

During ICIS-2007, the MINC instrument sampled directly from the APC chamber. The MINC was operated to measure ice nuclei concentrations while slowly increasing supersaturation (SS) at steady sample temperatures between -15 and $-33^{\circ} \mathrm{C}$. These "supersaturation scans" were performed by lowering the inner wall temperature and increasing the outer wall temperature from a common start temperature; this process is entirely manual and required close monitoring. As can be seen in Fig. 7, the sample temperature can vary by $\sim 1{ }^{\circ} \mathrm{C}$ over a supersaturation scan. Each scan took up to $30 \mathrm{~min}$ to complete. Faster scans are possible but this would be at the expense of accuracy in determining the fraction of particles activating at specific $T$ and SS conditions. Testing during ICIS-2007 showed that MINC can operate at supersaturations up to $6 \%$ (with respect to water) at $-25^{\circ} \mathrm{C}$ before water droplets are able to pass through the droplet evaporation zone at sizes large enough to be counted. At ICIS-2007, the aim was to scan up to $5 \%$ supersaturation with respect to water. Unfortunately, as temperature calibrations were carried out post-workshop, supersaturation scans very rarely passed water saturation. Based on the wall temperatures attained during ICIS-2007, Fig. 8 shows the range of sample conditions available when using MINC to test the activity of IN.

Results were obtained by MINC for all samples listed in Table 1 except the live bacteria sample: results for Arizona Test Dust (ATD), Saharan Dust (SD) and Snomax ${ }^{\circledR}$ are shown in this paper. While MINC did sample the soot aerosol samples, the temperatures required for these soot samples to be effective IN were much lower than those which could be achieved in MINC and so are not reported here.

\subsection{Detection of IN}

Figure 7 shows a time series of sample temperature, supersaturation and the number of particles $>3 \mu \mathrm{m}$ detected by the CLiMET counter when measuring Arizona Test Dust (ATD). This is the real-time information available to the user when operating the MINC. To allow comparison with other instruments, MINC results are typically plotted as activated fraction (AF) against supersaturation with respect to water, where the activated fraction of IN is defined here as the as number of particles $>3 \mu \mathrm{m}$ divided by the total number of particles initially entering the instrument. The $3 \mu \mathrm{m}$ threshold 


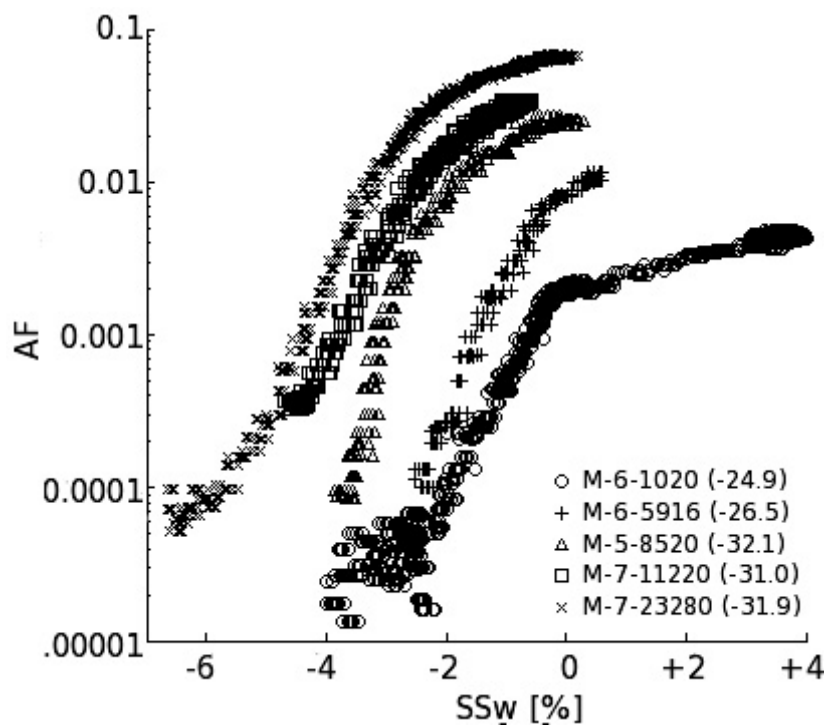

Fig. 9. Arizona test dust SS-scans performed by the MINC instrument. Legend: "M" - MINC instrument results, first number: sample preparation number, second number: seconds from the start of the experiment at which the scan began, number in brackets: temperature at which the scan was performed.

was used due to the limitations imposed by the optical particle counter.

\subsection{Results at different temperatures}

ATD was tested on three days and several SS-scans were performed over this period. Sample temperatures were -31 , $-28,-26$ and $-25^{\circ} \mathrm{C}$, results are shown in Fig, 9. The key result here was that at lower sample temperatures, lower supersaturations were required for the activated fraction to rise above the background. For the same supersaturation value, higher activated fractions were measured for lower sample temperature.

\subsection{Comparison of MINC measurements with those from other instruments}

The main aim of the workshop was to compare IN measurements by all the instruments present at the workshop, here the MINC results are compared to the CSU-CFDC instrument. This is a natural comparison since MINC is similar in many key aspects (e.g. geometry, inlet) to the CSU-CFDC design of Rogers et al. (2001) and unpublished modifications since that time. Throughout each day, several SS-scans were performed at different temperatures. Where possible, MINC performed scans at temperatures matching those of the CSU-CFDC to allow easier comparison between these instruments.

Results for ATD comparisons are shown in Fig. 10 for two sample temperatures $\left(\sim-25^{\circ} \mathrm{C}\right.$ and $\left.\sim-32^{\circ} \mathrm{C}\right)$; Fig. 10 also
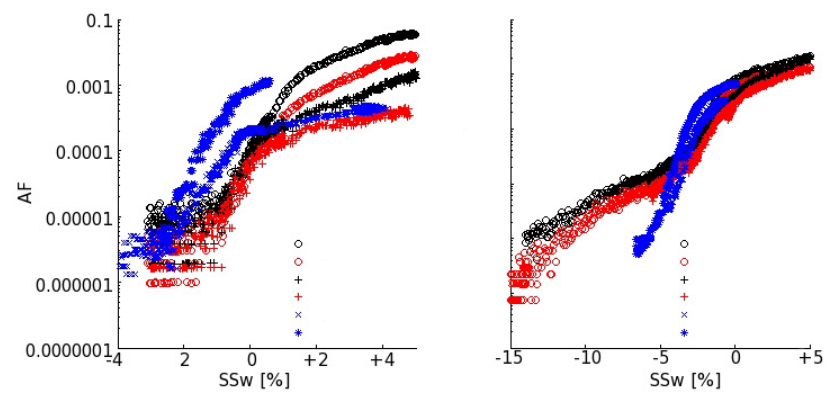

Fig. 10. Arizona test dust SS-scans. MINC results are shown in blue, CSU-CFDC results are shown in black ( $2 \mu \mathrm{m}$ threshold) and red $(3 \mu \mathrm{m}$ threshold). Results are shown for (a) Sample temperature $-25^{\circ} \mathrm{C}$, and (b) sample temperature $-31^{\circ} \mathrm{C}$. Legend: "M" MINC instrument results. "C" - CSU-CFDC instrument results, first number: sample preparation number, second number: seconds from the start of the experiment at which the scan began, number in brackets: temperature at which the scan was performed.

shows the CSU-CFDC activated fractions recalculated using an activated ice size threshold of $3 \mu \mathrm{m}$ to simulate the MINC detection threshold. CSU activated fractions determined using the $3 \mu \mathrm{m}$ threshold are closer to the MINC data at higher $\mathrm{SS}_{\mathrm{water}}$ values, e.g. at $2 \% \mathrm{SS}_{\text {water }}$ activated fraction is reduced $50 \%$. However, this change was found to make a modest increase (up to $1 \%$ ) in the difference of the SS values attributed to activation, and is well within measurement uncertainties. Figure 10a shows activated fraction from CSU-CFDC scans under similar conditions varying by up to a factor of 5, MINC data varies from CSU-CFDC data by a similar amount, though points follow similar activated fraction versus $S S_{\text {water }}$ curves. Figure $10 \mathrm{~b}$ shows results from $-32{ }^{\circ} \mathrm{C}$, where much closer agreement between the results can be seen, especially above $-5 \% \mathrm{SS}_{\text {water }}$ and active fractions exceeding $10^{-3}$. Figure 11 plots the supersaturation (as $\mathrm{SS}_{\text {water }}$ ) at which an activated fraction of 1 in 1000 was recorded as reported by both MINC and CSU-CFDC for three different samples during ICIS-2007 as a function of sample temperature. Error bars are shown at $\pm 3 \%$ SS as per the calculations shown in Richardson 2009 which simulate conditions within a CFDC. This plot highlights the good agreement between the two instruments in determining the supersaturation at which IN activation begins at any given temperature.

\section{Discussion}

The MINC instrument performed successfully during first measurements at the ICIS-2007 workshop. Post workshop wall temperature calibration revealed that many scans did not reach much higher than $0 \% \mathrm{SS}_{\text {water }}$ : this restricts the number of SS scans where activated fraction can be compared with that reported by some of the other groups at the workshop. 


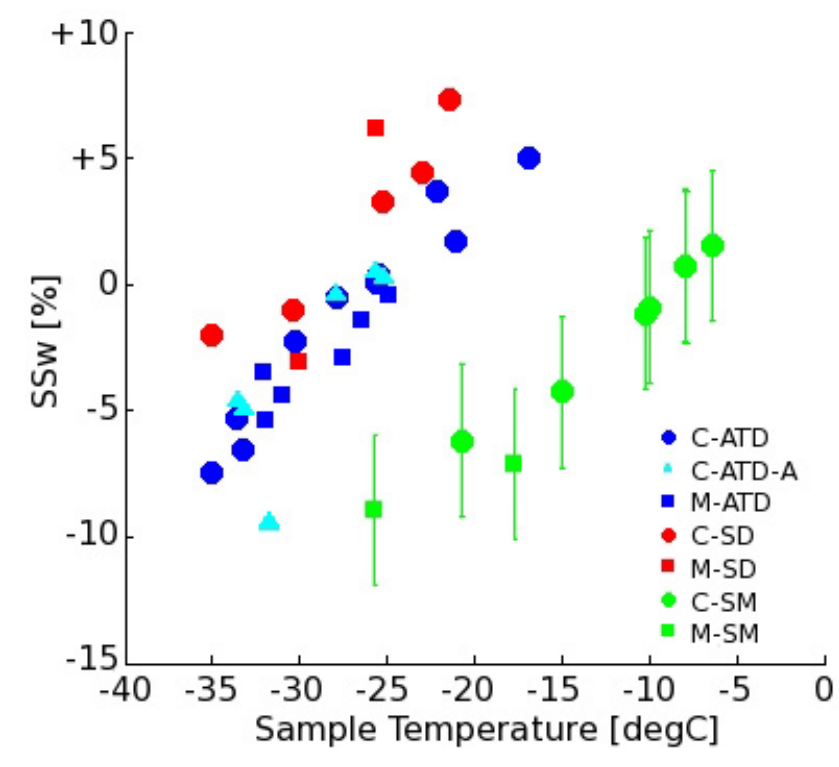

Fig. 11. Results from all MINC (squares) and CSU (circles) SSscans for Arizona Test Dust (blue), Saharan Test Dust (red) and Snomax ${ }^{\circledR}$ (green). Points represent the conditions at which the 1 in 1000 particles were activated. CSU adjusted data points are also shown (cyan triangles). $\mathrm{SS}_{\mathrm{water}}$ error bars are shown for Snomax ${ }^{\circledR}$ data (based on Richardson et al., 2010). The results shown in Figs. 9 and 10 are represented on this graph.

Figure 9, showing results solely from MINC for ATD samples, clearly highlights the dependence of IN activity on temperature and supersaturation.

Variations in activated fraction measured at different times by the same instrument (MINC or CSU-CFDC) under apparently similar conditions, as highlighted in Fig. 10a, may reflect spatio-temporal differences in the properties of the sample aerosol in the APC chamber. For example the C5-3785 curve (CSU-CFDC data from sample 5 starting at $3785 \mathrm{~s}$ from the reference time) in Fig. 10a is data from the morning of 17 September 2007, while the C-6-5875 curve is from the afternoon (note the new sample number). Between these measurements being made the APC chamber had been flushed and refilled with a fresh ATD sample. Even when the APC chamber was not refilled between scans the aerosol population within it evolved with time. MINC data shown in Fig. 10a were taken in the afternoon. If it is assumed that larger particles are more efficient IN than smaller particles, then the differences in the transmission efficiencies between the two instruments are important, particularly if the resultant aerosol size distribution sampled by the MINC has comparatively less larger particles, thus affecting the measured AF.

The MINC scans shown on Fig. 10a while taken on the same day as the CSU scans were not performed at the same times, being separated by $1 \mathrm{~h} 20 \mathrm{~min}$. Additionally MINC and CSU-CFDC sampled from different levels of the APC chamber during ICIS-2007 so results may also be affected by any stratification that occurred in the chamber as each instrument could have effectively been measuring different subset of the aerosol population in the APC chamber, although a mixing ventilator should have achieved homogeneous aerosol distribution throughout the chamber. These data show that measured activated fraction is very sensitive to the properties of the sample aerosol distribution (even for what should be the same sample) as well as the Temperature $(T)$ and SS conditions under which the IN measurement is made. Such variations in sample properties must be taken into account when comparing different instruments and efforts should be made to minimise these effects when conducting inter-comparison experiments. Figure 10a clearly shows substantial differences between results from different sample preparations (C-5-3785 and C-6-5875) when using the same instrument and similar sampling conditions.

When similar scans were performed at similar times as was the case for the $-32^{\circ} \mathrm{C}$ comparison shown in Fig. 10b there was very good agreement between the results. On these scans the CSU-CFDC appeared to detect deposition nucleation at lower SS which was not detected by MINC, this could be due to the differences in the design of the evaporation region or the longer transit time (and exposure to the vapour field) in the CSU instrument. This result could as well reflect onset conditions, at a temperature just moderately colder, for deposition nucleation, which was noted to become more dominant for ATD aerosols as temperature decreased toward $-40{ }^{\circ} \mathrm{C}$ in the CSU results (Koehler et al., 2010).

Comparisons of $T$ and SS conditions for IN activation to begin (defined here as an activated fraction of 1 in 1000), determined with both MINC and CSU-CFDC for experiments performed using three different samples showed very good agreement between the instruments (see Fig. 11). Data points for each of the sampled followed a separate trend, $R^{2}$ values from trend lines plotted through collective MINC and CSUCFDC data points are $0.93,0.78$ and 0.95 for ATD, SD and SM data respectively. Figure 11 also shows the CSU-CFDC results using the $3 \mu \mathrm{m}$ activation threshold for the ATD sample, and it can be seen that these data points are in most cases almost indistinguishable from the standard CSU-CFDC data.

During the AIDA workshop, elevated laboratory temperatures compared with those at the University of Manchester led to heat transfer to the ends of the chamber from those parts exposed to the laboratory (e.g. inlet system). This lead to increased difficulties in obtaining constant wall temperatures along the length of the chamber. As discussed in Sect. 2.3.2 tests with additional temperature sensors carried out post workshop revealed end effects extending over about $10 \mathrm{~cm}$ at each end of the chamber with a constant temperature region between. These experiments indicated that the middle temperature sensors should be used to determine sample temperature and supersaturation, and that the sample was exposed to the desired conditions for $\sim 4 \mathrm{~s}$ rather than $\sim 6 \mathrm{~s}$ as would have been the case under ideal conditions. We note 
here that, although the increase in the warm wall temperature at the copper/polypropylene interface increases the SS and sample temperature in this region of the chamber (and potentially activating extra IN), due to the short time before reaching the OPC any crystals activated at this point would not reach the detection limit for IN at the chamber exit and therefore not be counted.

In addition to variability in the sample aerosol in some experiments, discrepancies in the results between the MINC and CSU-CFDC instruments could be due to some, or all, of the following potential issues. In common with other optical particle counters, the modified CLiMET counter cannot distinguish multiple particles present simultaneously in the sample volume. Thus, once a particle event has started the counter is effectively dead to new particle events until a short time after all particles have exited the sample volume (this is referred to as the "dead-time"). The CliMET is expected to encounter significant dead time issues with particle concentrations of several tens of thousands per litre: this is not an issue when measuring under atmospheric conditions, but a definite issue when sampling during ICIS-2007. Differences in the way the signal from the CliMET was handled by the two instruments may lead to some differences in reported counts under these conditions. Secondly, the choice of threshold for determining the presence of IN within the chamber should be linked to the impactor cut-off $(1.3 \mu \mathrm{m}$ for MINC) however, due to a difference in dead-time between the two gain stages on the CliMET, data could only be used from the low gain channel, limiting the MINC threshold to $3 \mu \mathrm{m}$. The CSU instrument typically uses a $2 \mu \mathrm{m}$ threshold. When the CSU data were re-analysed using a $3 \mu \mathrm{m}$ threshold this did bring the results into closer agreement at higher values of $\mathrm{SS}_{\text {water }}$ (less than a factor of 5 difference as seen in Fig. 10), although it is important to consider other sampling issues that may have existed. This result illustrates the importance regarding the consideration of the size-cut for what is determined to be an IN, particularly when comparing instruments where this can clearly make a substantial difference in the reported activated fraction. Two of the major differences between the two instruments compared here is the length of the chamber and the water droplet evaporation section. The CSU-CFDC has a longer chamber and therefore additional ice crystal growth time, and has an actively-cooled evaporation section. The MINC has a passive evaporation section, which in the high temperatures experienced at ICIS-2007 could have resulted in the evaporation of ice crystals, and thus fewer crystals reaching the detection threshold. Despite these differences, when considering sample temperatures and supersaturation at the point where the activated fraction reaches 1 in 1000 , the results from the MINC and CSU instruments show excellent agreement, with instrument-instrument variability similar in magnitude to sample-sample variability.

\section{Conclusions}

Initial results from the Manchester Ice Nucleation Counter (MINC), collected during the ICIS-2007 workshop are reported here. Measurements of ice nuclei are compared to the results from the CSU-CFDC instrument, which is of similar design. Results show that MINC and CSU-CFDC detected similar numbers of IN in the samples shown while performing comparable SS-scans (see Fig. 11). For SS-scans performed at similar temperatures, activated fraction at any given SS value agreed to within one order of magnitude (worst case), and usually showed much closer agreement in activated fractions of different IN within SS measurement uncertainties.

While operating the MINC during the workshop, and when comparing the data produced with other instruments it became apparent that the current instrument had a number of limitations which could be overcome in future builds by modification of the design. Suggestions for improvements to the current design which should help to overcome the difficulties reported at ICIS-2007 are listed here: The chamber should be made longer to extend IN exposure time - it is suggested that the chamber be lengthened to allow a longer growth time and so easier detection of IN; Steps should be taken to improve the uniformity of wall temperatures - these might include increasing the number of refrigeration coils on both walls and improving the thermal contact between walls and coils; Extra temperature sensors down the length of both walls would increase the knowledge of and help constrain the sample conditions and subsequent calculations; Sample and sheath flows should be pre-cooled prior to entering the chamber thus reducing transient conditions at the top of the chamber, this can be achieved using a sub-coil from the refrigeration system. The refrigeration systems should also be modified to allow experiments at lower temperatures. The current passive water droplet evaporation region, should be replaced with an active evaporation section where the outer wall in this section is cooled to the same temperature as the inner wall - this would allow accurate determination of the conditions in the last section of the chamber.

It is particularly evident, when using a threshold size for ice detection, that increasing growth time and reducing evaporative losses will increase the activated fraction that a CFDC detects, especially in the water supersaturated regime. It is suggested that incorporating the use of phase detection within the counting system would be advantageous for IN detection systems. The use of this technique could remove the need for the impactor stage of the instrument, thus allowing a wider range of atmospheric particles to be tested. It is possible to distinguish between water, ice and marine boundary layer salt particles using backscatter depolarisation measurements, although it is not yet completely clear that there are no other particle types which could confound this technique. Despite this, in light of recent developments (e.g. Nicolet et al. 2010), it is believed that depolarisation based phase 
discrimination of particles does offer promise with regard to the application proposed here, particularly in the elimination of false counts due to supercooled water droplets.

These results show that the workshop has been successful in both providing excellent knowledge exchange between groups in this difficult area of research and that IN measurements in future will have a common basis for comparison following recommended improvements in current measurement systems.

Acknowledgements. Thanks to Paul Williams, Richard Hartley and workshop staff at The University of Manchester. First author would like to thank Tony Prenni from CSU for his support, particularly during the development stages. The Karlsruhe Institute of Technology provided funding during ICIS-2007 for the facility infrastructure within the Helmholtz Research Programme "Atmosphere and Climate". We acknowledge Ottmar Möhler and Olaf Stetzer for their roles in co-organizing the ICIS-2007 workshop. Thanks to the AIDA staff members for their support during the ICIS-2007 workshop. We also thank Thomas Schwartz (Karlsruhe Institute of Technology) for support in preparing the bacterial cultures, Eli Ganor (Tel Aviv University) for providing the Israeli dust sample, and Hans Moosmüller (Desert Research Institute) for providing the Canary Island dust sample. Collaborative work with the UK Met Office was funded by the DIAC-UKAAN Aerosol Knowledge Transfer program. Attendance to the ICIS-2007 workshop was funded by the ACCENT Access to Infrastructures Program, the University of Manchester contribution to the workshop was funded by NERC. Attendance at the 2008 results workshop was funded by ESF/INTROP. Paul DeMott acknowledges funding support for this research from the US National Science foundation grant ATM-0611936.

Edited by: D. J. Cziczo

\section{References}

Al-Naimi, R. and Saunders, C. P. R.: Ice nucleus measurements: effect of site location and weather. Tellus, 37B, 296-303. 1985

Bergeron, T.: On the low-level redistribution of atmospheric water caused by orography, in: Suppl. Proceedings of the International Conference on Cloud Physics, Tokyo and Sapporo, 24 May-1 June, 96-100, 1965

Bigg, E. K.: Long-term trends in ice nucleus concentrations, Atmos. Res., 25(5), 409-415, 1990.

DeMott, P. J., Petters, M. D., Prenni, A. J., Carrico, C. M., Kreidenweis, S. M., Collett, J. L., and Moosmüller, H.: Ice nucleation behavior of biomass combustion particles at cirrus temperatures, J. Geophys. Res., 114, D16205, doi:10.1029/2009JD012036, 2009.

DeMott, P. J., Prenni, A. J., Liu, X., Kreidenweis, S. M., Petters, M. D., Twohy, C. H., Richardson, M. S., Eidhammer, T., and Rogers, D. C.: Predicting global atmospheric ice nuclei distributions and their impacts on climate, Proceedings of the National Academy of Sciences, 107 (25), 11217-11222, 2010a.

DeMott, P. J., Möhler, O., Stetzer, O., Murakami, M., Leisner, T., Bundke, U., Klein, H., Kanji, Z., Cotton, R., Jones, H., Petters, M. D., Benz, S., Brinkmann, M., Rzesanke, D., Saathoff, H., Nicolet, M., Gallavardin, S., Saito, A., Nillius, B., Bingemer, H.,
Abbatt, J., Ardon, K., Levin, Z., Ganor, E., Georgakopoulos, D. G., Saunders, C., Vali, G.: Resurgence in ice nuclei measurement research, B. Am. Meteorol. Soc., in review, 2010 b.

Denman, K. L., Brasseur, G., Chidthaisong, A., Ciais, P., Cox, P. M., Dickinson, R. E., Hauglustaine, D., Heinze, C., Holland, E., Jacob, D., Lohmann, U., Ramachandran, S., da Silva Dias, P. L., Wofsy S. C., and Zhang, X.: Couplings Between Changes in the Climate System and Biogeochemistry. In: Climate Change 2007: The Physical Science Basis. Contribution of Working Group I to the Fourth Assessment Report of the Intergovernmental Panel on Climate Change, edited by: Solomon, S., Qin, D., Manning, M., Chen, Z., Marquis, M., Averyt, K. B. Tignor, M., Miller, H. L., Cambridge University Press, Cambridge, UK and New York, NY, USA. 2007

Dymarska, M., Murray B. J., Sun, L., Eastwood, M. L., Knopf, D. A., and Bertram, A. K.: Deposition ice nucleation on soot at temperatures relevant for the lower troposphere, J. Geophys. Res., 111, D04204, doi:10.1029/2005JD006627, 2006.

Eidhammer, T., DeMott, P. J., Rogers, D. C., Prenni, A. J., Petters, M. D., Twohy, C. H., Rogers, D. C., Stith, J., Heymsfield, A., Wang, Z., Haimov, S., French, J., Pratt, K., Prather, K., Murphy, S., Seinfeld, J., Subramanian, R., and Kreidenweis, S. M.: Ice initiation by aerosol particles: Measured and predicted ice nuclei concentrations versus measured ice crystal concentrations in an orographic wave cloud, accepted, J. Atmos. Sci., 2010.

Elliott W. P.: Dimensions of thermal diffusion chambers. J. Aerosol Sci., 28, 810-811, 1971.

Forster, P., Ramaswamy, V., Artaxo, P., Berntsen, T., Betts, R., Fahey, D. W., Haywood, J., Lean, J., Lowe, D. C., Myhre, G., Nganga, J., Prinn, R., Raga, G., Schulz, M., and Van Dorland, R.: Changes in Atmospheric Constituents and in Radiative Forcing, Climate Change, 2007: The Physical Science Basis. Contribution of Working Group I to the Fourth Assessment Report of the Intergovernmental Panel on Climate Change, edited by: Solomon, S., Qin, D., Manning, M., Chen, Z., Marquis, M., Averyt K. B., Tignor, M., Miller, H. L., Cambridge University Press, Cambridge, UK and New York City, NY, USA, 2007.

Fukuta, N. and Saxena, V. K.: Horizontal Thermal-Gradient Cloud Condensation Nucleus Spectrometer, J. Appl. Meteorol., 18(10), 1352-1362, 1979.

Kanji, Z. A. and Abbatt, J. P. D.: The University of Toronto Continuous Flow Diffusion Chamber (UT-CFDC): A Simple Design for Ice Nucleation Studies. Aerosol Science and Technology, 43, 730-738, doi:10.1080/02786820902889861, 2009.

Knopf, D. A. and Koop, T.: Heterogeneous Nucleation of Ice on Surrogates of Mineral Dust, J. Geophys. Res., 111(D12), D12201, doi:10.1029/2005JD006894, 2006.

Knudsen, J. G. and Katz, D. L.: Fluid dynamics and heat transfer, McGraw Hill, NY, USA, 576 pp., 1958.

Koehler, K. A., Kreidenweis, S. M., DeMott, P. J., Petters, M. D., Prenni, A. J., and Möhler, O.: Laboratory investigations of the impact of mineral dust aerosol on cold cloud formation, Atmos. Chem. Phys., 10, 11955-11968, doi:10.5194/acp10-11955-2010,, 2010.

Kulkarni, G., Dobbie, S., and McQuaid, J. B.: A new thermal gradient ice nucleation diffusion chamber instrument: design, development and first results using Saharan mineral dust, Atmos. Meas. Tech., 2, 221-229, doi:10.5194/amt-2-221-2009, 2009.

Meyers, M. P., DeMott, P. J., and Cotton, W. R.: New primary ice- 
nucleation parametrisations in an explicit cloud model. J. Appl. Meteorol., 31(7), 708-721, 1992.

Möhler, O., Stetzer, O., Schaefer, S. Linke, C., Schnaiter, M., Tiede, R., Saathoff, H., Kramer, M., Mangold, A., Budz, P., Zink, P., Schreiner, J., Mauerberger, K., Haag, W., Karcher, B., and Schurath, U.: Experimental investigation of homogeneous freezing of sulphate acid particles in the aerosol chamber AIDA, Atmos. Chem. Phys., 3, 211-223, doi:10.5194/acp-3-221-2003, 2003.

Möhler, O., Field, P. R., Connolly, P., Benz, S., Saathoff, H., Schnaiter, M., Wagner, R., Cotton, R., Kramer, M., Mangold, A., and Heymsfield, A. J.: Efficiency of the deposition mode ice nucleation on mineral dust particles, Atmos. Chem. Phys., 6, 3007-3021, doi:10.5194/acp-6-3007-2006, 2006.

Möhler, O., DeMott, P. J., Stetzer, O., the ICIS-2007 team: The Fourth International Ice Nucleation Workshop ICIS-2007. Proceedings to the $15^{\text {th }}$ International Conference on Clouds and Precipitation, Cancun, Mexico, 7-11 July, 2008a.

Möhler, O., Georgakopoulos, D. G., Morris, C. E., Benz, S., Ebert, V., Hunsmann, S., Saathoff, H., Schnaiter, M., and Wagner, R.: Heterogeneous ice nucleation activity of bacteria: new laboratory experiments at simulated cloud conditions, Biogeosciences, 5, 1425-1435, doi:10.5194/bg-5-1425-2008, 2008b.

Murphy, D. M. and Koop, T.: Review of the vapour pressures of ice and supercooled water for atmospheric applications, Q. J. Roy. Meteorol. Soc., 131, 1539-1565, 2005

Nicolet, M., Stetzer, O., Lüönd, F., Möhler, O., Lohmann, U.: Single ice crystal measurements during nucleation experiments with the depolarization detector IODE. Atmos. Chem. Phys., 10, 313325, doi:10.5194/acp-10-313-2010, 2010.

Richardson, M. S., DeMott, P. J., Kreidenweis, S. M., Petters, M. D., and Carrico, C. M.: Observations of ice nucleation by ambient aerosol in the homogeneous freezing regime, Geophys. Res. Lett., 37, L04806, doi:10.1029/2009GL041912, 2010.
Rogers, D. C.: Development of a continuous flow thermal gradient diffusion chamber for ice nucleation studies, Atmos. Res., 22, 149-181, 1988.

Rogers, D. C., DeMott, P. J., Kreidenweis, S. M., and Chen, Y. L.: A continuous-flow diffusion chamber for airborne measurements of ice nuclei, J. Atmos. Ocean. Tech., 18(5), 725-741, 2001.

Saxena, V. K., Burford, J. N., and Kassner, J. L.: Operation of a Thermal Diffusion Chamber for Measurements on Cloud Condensation Nuclei. J. Atmos. Sci., 27(1), 73-75, 1970.

Sinnarwalla, A. M. and Alofs, D. J.: A cloud nucleus counter with long available growth time, J. Appl. Meteorol., 12, 831-835, 1973.

Stetzer, O., Baschek, B., Luond, F., and Lohmann, U.: The Zurich Ice Nucleation Chamber (ZINC) - A new instrument to investigate atmospheric ice formation, Aerosol Sci. Tech., 42, 64-74, 2008.

Szyrmer, W. and Zawadzki, I.: Biogenic and anthropogenic sources of ice forming nuclei: A review, B. Am. Meteor. Soc., 78(2), 209-228, 1997.

Vali, G.: Nucleation Terminology, B. Am. Meteor. Soc., 66, 1426$1427,1985$.

Vali, G.: Ice Nucleation Workshop, Summary Report, University of Wyoming, Laramie, USA, 18 pp., 1975.

Williams, P. I., McFiggans G., and Gallagher M. W.: Latitudinal aerosol size distribution variation in the Eastern Atlantic Ocean measured aboard the FS-Polartern, Atmos. Chem. Phys., 7, 1-11, doi:10.5194/acp-7-1-2007, 2007. 